\title{
Computer science experimenter's kit for use in preschool and primary school
}

\author{
Anja Gärtig-Daugs \\ University of Bamberg \\ An der Weberei 5 \\ 96047 Bamberg \\ ++49-863-1236 \\ anja.gaertig-daugs@ \\ uni-bamberg.de
}

\author{
Katharina Weitz \\ University of Bamberg \\ An der Weberei 5 \\ 96047 Bamberg \\ ++49-863-2874 \\ feli.kogsys@ \\ uni-bamberg.de
}

\author{
Maike Wolking \\ University of Bamberg \\ An der Weberei 5 \\ 96047 Bamberg \\ ++49-863-2874 \\ feli.kogsys@ \\ uni-bamberg.de
}

\author{
Ute Schmid \\ University of Bamberg \\ An der Weberei 5 \\ 96047 Bamberg \\ ++49-863-2860 \\ ute.schmid@ \\ uni-bamberg.de
}

\begin{abstract}
In this paper, we describe a didactic concept for the impartation of elementary computer science competences in early childhood education and primary school. Illustrative material, experimenting material, and a manual for (preschool) teachers have been conceptualized. The experimenter's kit covers the topics "Computer scientists", "Pixel", "Digital and analog representation", "Computer and its components", "Algorithms", and "Search and sorting algorithms". Material has been evaluated by educators and preschool children in 2 preschools. Evaluation focuses on handling of manual and material by preschool teachers, appropriateness of material for children aged 5 to 6 years, and intended future use of material. Data collection has been based on standardized questionnaires and participatory observation. Our results show that the manual and illustrative materials are suitable for use by educators without computational background. Predominantly, children can easily handle the experimenting material and like playing with it. A pilot test of material in primary school is pending.
\end{abstract}

\section{CCS Concept}

Social and professional topics - Computing education Computing education programs - Computer science education

\section{Keywords}

elementary computer science education; primary computer science education; experimenter's kit; experimenting material; field study; pilot test; educators; preschool; kindergarten

\section{INTRODUCTION}

Nowadays, computer science influences our everyday life. Children grow up getting in contact with lots of technical devices. In our opinion, it is necessary to teach children not only to use these technical achievements, but also to understand the computational concepts behind these devices. Therefore, we

Permission to make digital or hard copies of all or part of this work for personal or classroom use is granted without fee provided that copies are not made or distributed for profit or commercial advantage and that copies bear this notice and the full citation on the first page. Copyrights for components of this work owned by others than the author(s) must be honored. Abstracting with credit is permitted. To copy otherwise, or republish, to post on servers or to redistribute to lists, requires prior specific permission and/or a fee. Request permissions from Permissions@acm.org.

WiPSCE '16, October 13 - 15, 2016, Münster, Germany.

Copyright is held by the owner/author(s). Publication rights licensed to ACM.

ACM 978-1-4503-4223-0/16/10 ..\$15.00

DOI: http://dx.doi.org/10.1145/2978249.2978258 developed a didactic concept that brings together knowledge about the application of technical devices and the computational concepts behind these devices. That way, we want to help children understand the world they live in.

Another reason for the design of our "Computer Science Experimenter's Kit" is that children should have the chance to discover their abilities and talents in computer science - regardless of their gender and social background. It is often suggested that initiatives to awake and foster interest for STEM subjects should start in preschool [12][17] and continue in primary and higher education. However, educational programs that address preschool children and allow them to get in touch with computer science are rare [14].

\section{PEDAGOGICAL APPROACH}

\subsection{Theoretical background}

For children, it is normal to explore their environment using everyday things. Rousseau described "things" as one of the main "teacher" of the child. Froebel's elementary pedagogical principle to show the world in and through the things opens up the world for children and allows them to discover it in an orderly and physically explorable form - even in preschool. Like Froebel, Maria Montessori recognized the educational meaning of things and used them as the foundation of her developed materials [8]. The constructivist approach argues, like Dewey described it, that knowledge is generated through the experiences that are meaningful and important to learning people [6]. Our "Computer Science Experimenter's Kit" wants to combine these early and still actual ideas to teach children by using things of their everyday surrounding and providing hands-on experiences. That way, children shall be enabled to autonomously create realistic, child-oriented models of their world. This is important to prepare children for the growing technological environment which is getting more and more complex [13]. Children shall construct their own knowledge by testing ideas based on previous experiences and knowledge [15]. Therefore, our concept is based on learning by analogical comparison and reasoning. That is, a current problem is solved by retrieving a previously solved problem from memory and generalizing over the common structure of both problems [11][16]. Analogical comparison has been demonstrated to be a powerful mean to help children learn key scientific and engineering principles [7].

Whereas our previous "I4Kids" workshops for preschool and primary school children ${ }^{1}$ have been instructed by computer science experts, the idea of our "Computer Science

\footnotetext{
${ }^{1}$ http://nachwuchs.wiai.uni-bamberg.de/i4kids.html
} 
Experimenter's Kit" is that (preschool) teachers without deepened computational competences can use it. Therefore, we developed an elaborate manual ${ }^{2}$.

Thus, the two pillars of our concept are: a manual for (preschool) teachers and illustrative and experimenting material for children.

\subsection{Practical implementation}

\subsubsection{Manual for (preschool) teachers}

The manual for (preschool) teachers is designed such that laymen who have not studied computer science can explain the main computational concepts and introduce the experimenting material to the children.

Every topic is segmented in the same sections:

- an initial question which will be answered in the chapter, a list of illustrative material needed to explain the topic,

"lesson learned" goals for children,

- background knowledge about the topic for the (preschool) teacher,

a detailed description of the accomplishment,

- and a description of the experimenting material for the children.

\subsubsection{Illustrative and experimenting material}

In addition to the manual, the experimenter's kit contains two types of material which are highly interactive. On the one hand, this is the illustrative material that can be used to explain a topic to the children. It is designed to help the (preschool) teacher to introduce and to illustrate the topics. On the other hand, this is the experimenting material. After it has been introduced, children can use it without further instruction by a (preschool) teacher. This material adopts the basic idea of Maria Montessori, expressed in her statement "Help me to do it by myself". It enables the "unplugged" exploration of computational concepts [2]. The experimenting material consists of games that animate children not only to reproduce the illustrative example but to solve new problems by analogical reasoning. The games come in different levels of difficulty and are designed to correspond to cognitive capabilities of children aged 5 to 6 years, 6 to 8 years $\left(1^{\text {st }}\right.$ and $2^{\text {nd }}$ grade in primary school), and 8 to 10 years $\left(3^{\text {rd }}\right.$ and $4^{\text {th }}$ grade in primary school). The understanding of computational concepts is further deepened by the employment of device-based examples and computer applications, as far as useful applications for children exist. The material is designed to be used by pairs or groups and for project-based learning. Working in a project can influence motivation positive and help children to understand topics [4].

\subsubsection{Topics of the experimenter's kit}

The topics of the experimenter's kit are connected to the everyday context of children.

Computer scientists. Children are interested in vocational fields of their parents and other people they know. These experiences contribute to the early formation of vocational attitudes and beliefs and influence early career aspirations [9]. Therefore, it is important for us to give a realistic, non-stereotype picture of the vocational field of a computer scientist. In addition, we give an overview of the differences between past and present computer scientists and describe the modern fields of computer science applications.

${ }^{2}$ Available by email from Ute Schmid.
Pixel. Children typically like drawing. We use this interest to start with the initial question "How does a computer represent pictures?". The topic is introduced by comparing hand-drawn and computer-drawn pictures. After that comparison, the general concept of representing pictures by pixels will be illustrated (see Figure 1). Finally, children are presented the experimenting material and asked to create binary images by coloring all fields of a picture that are marked with " 1 " (see Figure 2).

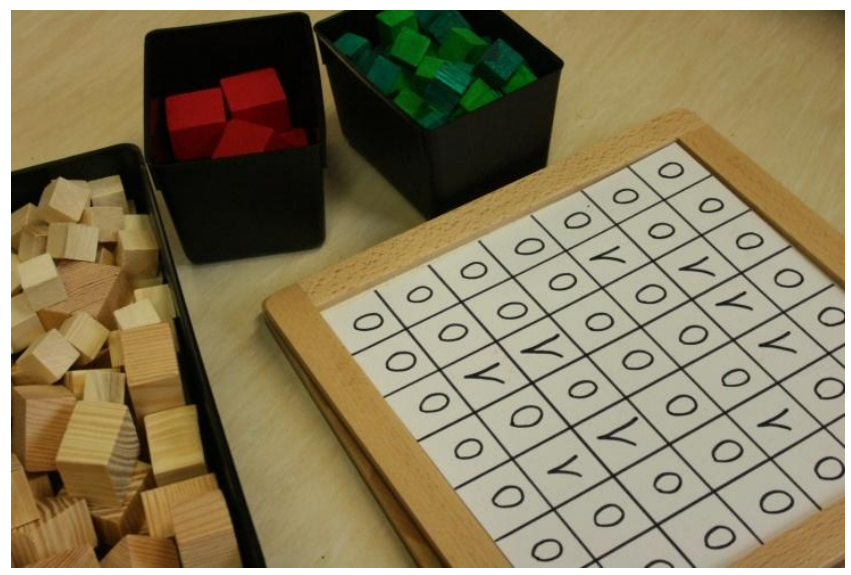

Figure 1: Illustrative material designed for "Pixel"

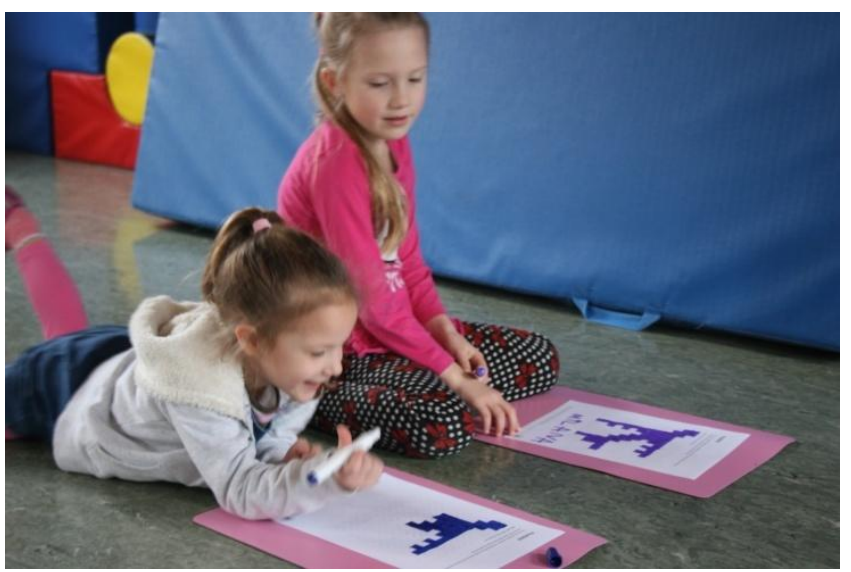

Figure 2: Children using the experimenting material designed for "Pixel"

Analog and digital representations. Based on the topic pixel, the difference between analog and digital representations is considered. Children like and are used to taking pictures with the camera or smart phone of their parents. Therefore, we use digital and analog photography to illustrate the distinction between the terms analog and digital. One of the corresponding experimenting materials consists of "Pixel stickers": Children draw a simple analog picture on a squared paper. Analogous to the "Pixel" experimenting material, children paste up every box that is colored with "Pixel stickers".

Computer and its components. The previous units focused on the several steps in the process to create a digital picture. In this unit, we look inside the computer and consider the components that are involved in creating, saving, changing, and printing pictures. Therefore, original parts of a computer (e.g., processor, hard disk, or cooler) are handed out to the children. Children can touch, look at, and compare them. After an exploration of the different computer parts, we combine the knowledge of pixel/digital painting with the functionality of a computer by 
introducing a child-friendly digital painting program, called Tux Paint ${ }^{3}$. Therefore, the experimenter's kit comprises 2 tablets with touch display on which Tux Paint operates. An additional part of this topic is the illustrative presentation of the historical development of computers, like the first calculating machine.

Algorithms. The objective of this topic is to look behind the surface of a computer. The central question of this topic is "What is an algorithm?" in order to give children an insight into how a computer handles problems. The idea of an algorithm, e. g., that a set of defined instructions is needed to solve a given problem, is illustrated by a cooking receipt. After the introduction to the topic, children may experiment and explore the functioning of algorithms by their daily routines such as "waking up and getting up in the morning".

Search and sorting algorithms. The last topic is a little glimpse to further topics which will be precisely explained and explored in primary school. In their daily life, children get in contact with sorting problems such as the sorting of toys. The initial question of this topic is "Why is it useful to sort things?". The Selection Sort algorithm is illustrated by picture cards with objects such as animals, trees, or houses of different sizes. The children experience that it is easier to retrieve a certain element if all elements are ordered. The experimenting material consists of a beam balance and visually identical objects of different weights. Children are asked to figure out a way to identify the lightest object [2].

\section{PILOT TEST}

\subsection{Methodology}

The evaluation was driven by the following research questions:

- Does the provision of an experimenter's kit provide the opportunity to implement computer science education in elementary education?

- Are the manual and the illustrative material suitable for (preschool) teachers without computational background?

- Is the material appropriate for children aged 5 to 6 years?

We supposed that the experimenter's kit will enable the integration of computational concepts in elementary education if the manual is comprehensive, if time needed for reading the manual and preparation of a session is short, if preschool teachers are interested in the topics covered by the experimenter's kit and have fun instructing the sessions, and if they intend to use the material in future. Furthermore, we hypothesized that our concept will be suitable for use by persons without computational background if the manual gives all relevant background knowledge. So we asked for questions that remained unanswered after having read the manual. We also supposed that material will be appropriate for 5 to 6 years old children if the material meets the motoric and cognitive abilities of children, if children are interested in the topic, if they enjoy playing with the material, and if they also use the material during their free playing time.

Based on these assumptions, we constructed a standardized questionnaire. Items were mostly measured based on a 5-point Likert scale (1: does not apply at all; 5: fully applies). Complementary, participating educators were asked to provide detailed feedback using an open response field. Data collection was based on a standardized questionnaire in order to give the respondents enough time to reflect the sessions and to receive critical and honest feedback [5].

\footnotetext{
${ }^{3}$ http://www.tuxpaint.org/
}

In addition, three researchers of the project team observed the sessions and answered open questions before a session was instructed. Participatory observation should give insights whether computational concepts were understood and correctly explained by preschool teachers, whether the experimenting material could be autonomously used by children, and whether girls were interested in the topics and experimenting as much as boys. Results of the participatory observation were discussed and only results all observers agreed on are reported.

\subsection{Setting and schedule of the pilot test}

The experimenter's kit was pilot-tested in two kindergartens.

Kindergarten 1 was located in a small town and Kindergarten 2 in a medium-sized town of Germany. Our field study focused on preschool children aged 5 to 6 years within their third year at kindergarten. In total, 25 children (13 girls, 12 boys) took part. All sessions took place over a period of six working days within two weeks.

The introductory unit "Computer scientists" was instructed by a member of the project team and is therefore not subject of evaluation by educators.

Kindergarten 1: In Kindergarten 1, all preschool children ( $\mathrm{n}=$ 12; 6 girls, 6 boys) could be included in the study. Sessions took place in the morning from 10:00 to 11:00. A female educator instructed the sessions. Three members of the project team observed the sessions.

Kindergarten 2: In Kindergarten 2, about half of the preschool children ( $\mathrm{n}=13 ; 7$ girls, 6 boys) were involved. The sessions took part during school holidays. During this period, some children with older sisters or brothers did not attend kindergarten. Selection of children was based on kindergarten attendance during the whole study period. Sessions took place in the morning from 9:30 to 10:30. A male teacher instructed the sessions. The three researchers of the project team who had observed the sessions in Kindergarten 1 also observed the sessions in Kindergarten 2.

\section{RESULTS}

\subsection{Evaluation of manual and material by preschool teachers}

In Figure 3, the assessment of the manual and the designed materials by participating preschool teachers is shown. In Kindergarten 1, one questionnaire was completed for each topic. In Kindergarten 2, the illustrative and experimenting material designed for "Search and sorting algorithms" was separately evaluated. Thus, six questionnaires were filled in.

Both educators who instructed the sessions had no computational background. However, they assessed the manual as comprehensible and were able to illustrate the topics and to introduce the experimenting material to the children after having read the manual. Educator 1 stated that the chapters "Analog and digital representation" and "Algorithms" were harder to comprehend. Educator 2 said that all parts were (very) well comprehensible, especially the topic "Computer and its components". In Kindergarten 1, open questions were related to the functionality of the presented computer parts, the game instruction belonging to the exploring of daily routines by given picture cards and the working of the Selection Sort algorithm. In Kindergarten 2, there were no unresolved questions after the educator read the manual. Participatory observation revealed that computational concepts had been mainly understood by the participating preschool teachers and were correctly explained to children. Some misunderstanding was related to the topic (sorting) 
algorithm. Educator 1 thought that the computer would have to sort algorithms instead of sorting elements by given algorithms.

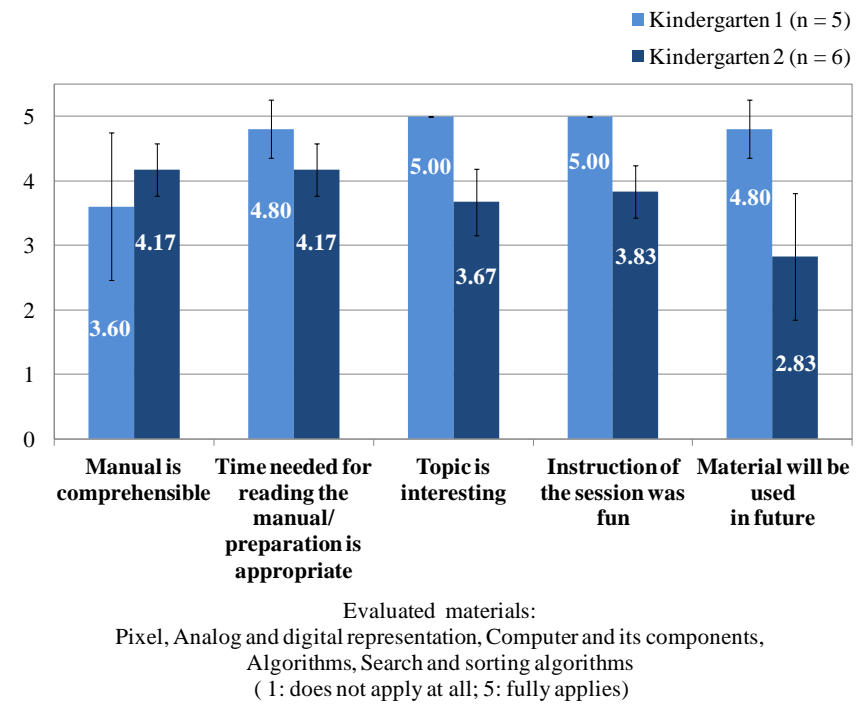

Figure 3: Assessment of materials by participating preschool teachers (mean scale scores and error indicators showing standard deviations)

Time needed for reading the manual and preparation of a session of one hour was assessed as highly appropriate. Time needed varied between 5 to 30 minutes. Most time was needed for reading the manual and mental preparation. Due to the experimenter's kit which provides all material that is needed for a specific topic, illustrative and experimenting material could be taken out and arranged within few minutes. Written feedback and participatory observation revealed that photos of the material should be included in the manual. In this way, the preparation of a session could be further eased.

Personal interest for computational topics that were covered by the experimenter's kit slightly varied between both educators. Educator 1 was very interested in all topics. Educator 2 also demonstrated a high interest with exception of the topic "Pixel" and the sorting experiment based on the beam balance (rated 3 out of 5 vs. a rating of 4 for each other topic).

Interest for the topic was correlated with having fun when instructing the session. Educator 1 stated that she had always great fun when she instructed the session and explored computational concepts with the children. Similarly, Educator 2 said that he enjoyed the instruction of the session with exception of the topic "Algorithms" (rated 3 out of 5 vs. a rating of 4 for each other topic).

With regard to the intended future use of materials, the assessments of both kindergartens differed. While Kindergarten 1 highly intended to use all materials in future, Kindergarten 2 is less enthusiastic. Figure 4 provides more detailed insights.

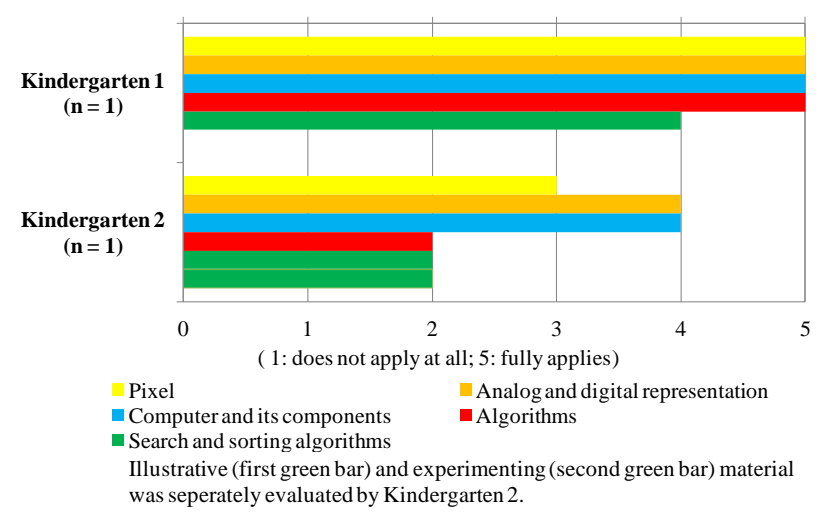

Figure 4: Intended future use by material

Kindergarten 1 stated that all designed materials will be probably used in future. In particular, written feedback revealed that the "Pixel coloring pictures" (experimenting material designed for Pixel) were highly appreciated by children and more templates would be highly welcomed. The topic "Search and sorting algorithms" was rated somewhat lower (4 out of 5) but it is also envisaged to integrate this topic in future computer science lessons. Kindergarten 2 intended to use the material designed for "Analog and digital representation" and "Computer and its components" in future. However, it was stated that future use of the digital painting program Tux Paint may require smaller groups or more tablets. The kindergarten had no own tablets and only few laptop computers that were typically used for administrative purposes by educators and not thought to be used by children. The material designed for "Pixel" is seen as a basis for the following topics. However, Kindergarten 2 will use it in future only if multiple sets of the illustrative material are available so that the material can be used to introduce the topic to smaller groups of children. The topics "Algorithms" and "Search and sorting algorithms" will probably not be used in future. Educator 2 stated that the topics would be too theoretical for children. He also criticized that computer applications were missing. Therefore application knowledge could not be imparted to children and a deeper understanding of the computational concepts could not be realized.

\subsection{Evaluation of appropriateness of material for children}

In total, illustrative and experimenting material was assessed as highly adequate for children aged 5 to 6 years (see Figure 5). Only, the material designed for "Analog and digital representation" was rated slightly lower than other topics by Kindergarten 2 (rated 3 out of 5 vs. an average rating of 4.25 for all other topics).

With regard to motoric requirements, both kindergartens stated that the material could be very well handled by children. However, participatory observation revealed that children who worked with a laptop computer instead of a tablet with touch display had some problems to control the computer with a mouse. 


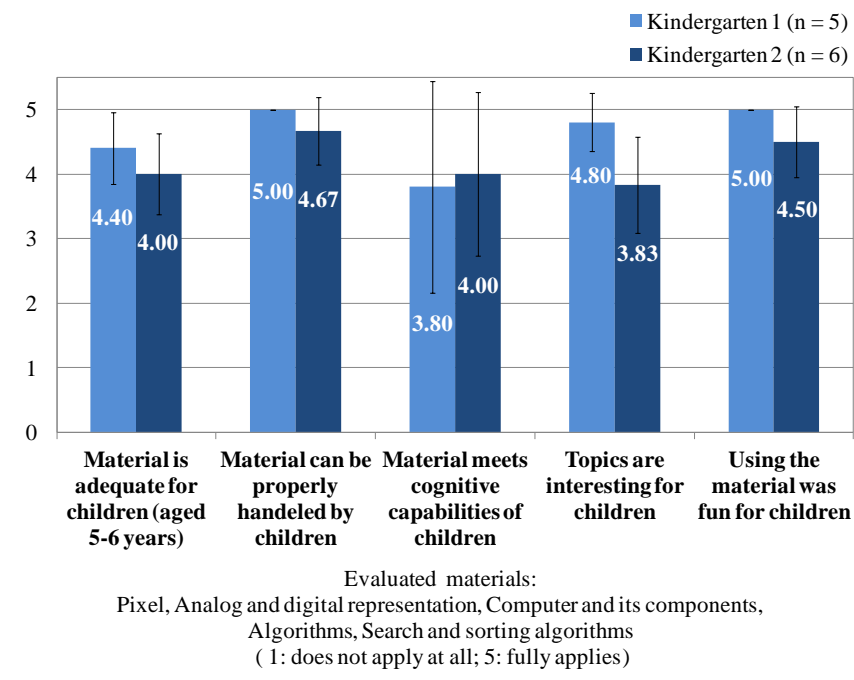

Figure 5: Assessment of appropriateness of material for children (mean scale scores and error indicators showing standard deviations)

Both kindergartens differed concerning the question whether the material met the cognitive abilities of children aged 5 to 6 years. Figure 6 provides deeper insights.

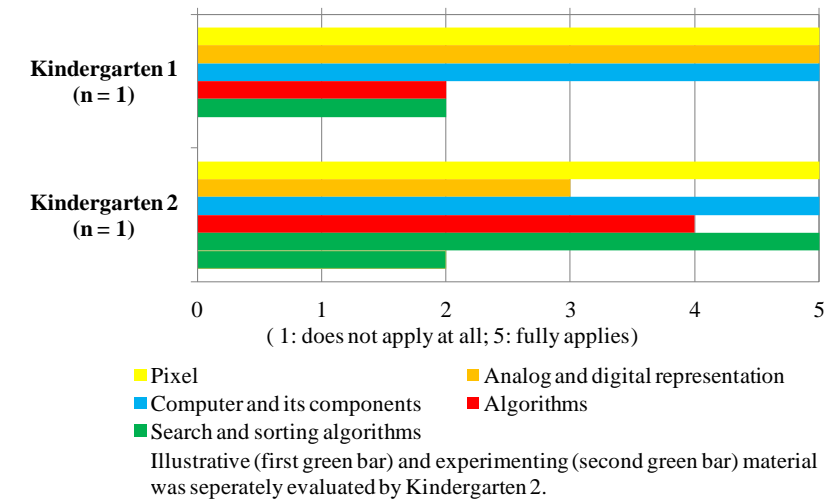

Figure 6: Assessment of accordance of cognitive abilities of preschool children and cognitive requirements

Kindergarten 1 thought that material designed for "Pixel", "Analog and digital representation" and "Computer and its components" would correspond very well to cognitive abilities of preschool children. In contrast, Kindergarten 1 stated that children had problems to understand how they should use the material belonging to "Algorithms" and "Search and sorting algorithms". This personal assessment is in accordance with the results of the participatory observation. In Kindergarten 1, children used the experimenting material for "Pixel" and "Analog and digital representation" autonomously, explored the various painting options offered by Tux Paint and knew that the pictures they painted were represented by pixels. However, they needed the support of the educator who had to give detailed instructions how to use picture cards that showed daily routines or the beam balance to figure out the lightest object. In addition, children found the Selection Sort algorithm too cumbersome because - in contrast to a computer - they were able to remember under which sorting card the smallest element was hidden. In the opinion of Kindergarten 2, material designed for "Pixel", "Computer and its components", Algorithms", and the sorting cards used to illustrate the Selection Sort algorithm would correspond (very) well to cognitive abilities of preschoolers. With regard to "Analog and digital representation" and the experimenting material (beam balance) to explore the Selection Sort algorithm, Kindergarten 2 said that children liked playing with the cameras and the beam balance but they did not always link their experiences to the introduced computational concepts. This would be especially true for the beam balance experiment. This evaluation can be supported by participatory observation: children used the beam balance autonomously but they did not find a way to figure out the lightest object; they were more interested in balancing than in sorting objects.

Kindergarten 1 stated that the topics would be highly interesting for children. Only, the topic "Search and sorting algorithms" was rated a little bit lower (4 instead of 5 for each other topic). According to participatory observation, this might be attributed to the beam balance experiment which was less favored by children. Kindergarten 2 thought that most topics would be of higher or at least mediocre interest for children.

Both kindergartens said that children had (great) fun using the material and enjoyed the sessions. In Kindergarten 1, some material was also used during free playing time. Girls as well as boys especially liked to color Pixel pictures or to write down their daily routines in the form of an algorithm. Therefore, they wanted to repeat these games during their free playing time. In Kindergarten 2, due to organizational reasons, the children had no possibility to use the material during free playing time.

Participatory observation revealed that almost all girls and boys awaited each sessions with anticipation and showed huge interest in the presented topics and in experimenting with the materials. One girl from Kindergarten 1 and one girl and one boy from Kindergarten 2 were less interested in the sessions. They did not want to take part and/or were otherwise engaged during the sessions.

\section{DISCUSSION}

The data from our field study indicates that the provision of a "Computer Science Experimenter's Kit" is a feasible way to implement computer science education in elementary education. This supports the belief that learning with and about technologies is possible and interesting for children in preschool [10]. Due to the manual and the provided illustrative and experimenting material the time needed for preparation a lesson is relatively short. One major challenge was to create a manual and illustrative material that can be used by (preschool) teachers without experience in the field of computer science. Our results show that the main concept was implemented successfully. The manual is well comprehensible and provides the know-how needed by preschool teachers to impart computational concepts to children. Nevertheless, a few changes and additional explanations are needed: common misconceptions, a more detailed description of the topics "Analog and digital representation", "Algorithms", and "Search and sorting algorithms" and photos of the materials that are needed for a session will be included in the manual. Furthermore, multiple sets of illustrative and experimenting material will be provided. Thus, educators can work with smaller groups. Furthermore, theoretical computational concepts will be complemented by practical device-based applications whenever possible. So, some experimenting material based on the programming language $\mathrm{ScratchJr}^{4}$ will be added to the unit "Algorithms". We learned that it is important to use computer

\footnotetext{
${ }^{4}$ http://www.scratchjr.org/index.html
} 
devices with touch display so that children can focus on understanding of computational concepts rather than on handling a mouse. In most kindergartens, such tablets are missing. So, we will add more tablets with touch display to our experimenter's kit.

Previous research shows that technology integration and the influence on higher-order thinking skills depends on the teachers' openness to change [1]. Educators were open-minded towards the provision of elementary computational concepts in preschool. They were interested in the suggested topics and intended to use most of the materials in future. This may be due to the fun children had when they played with the material, the high interest of children in the introduced computational topics, or the proper handling and intensive use of material by children of both sexes. This can be seen as an indicator that our idea to combine the ideas of Froebel and Montessori with computer science is an appropriate method to explain technical and theoretical computational concepts to children.

However, it is not clear if the topics "Algorithms" and "Search and sorting algorithms" should remain part of computer science sessions in preschool. Some concerns were raised whether children are capable of linking the computational concepts to their everyday context and whether the material meets their cognitive abilities. In contrast, children liked structuring daily problems and visualizing them as algorithms. Therefore, we think that logical thinking should already be fostered in preschool and the elementary concept of algorithms should be introduced. However, some changes and simplifications seem to be necessary to make the computational concept of sorting and searching more comprehensible. Maybe children and educators need more time to understand these two topics. Lack of time and lack of effective training are known to be two reasons for poor understanding and poor using technology in school [3]. This may be also true for the impartation of more complex computational concepts. After all amendments have been made, the formative evaluation will continue in further kindergartens.

In another field study, we will test if our concept and the designed materials for children aged 6 years and older work well in primary schools. Furthermore, additional interesting topics for preschool children will be developed.

\section{ACKNOWLEDGMENTS}

We would like to express our special thanks to Silvia Förtsch, Daniel Knauf, and Prof. Dr. Frithjof Grell for valuable input on pedagogical principles, Anke Steinhäuser for her support during the pilot test, Hannah Deininger for data preparation, Michael Siebers for a critical discussion of this paper, three anonymous reviewers for their helpful comments that contributed to the improvement of this paper, and all participating educators and children for their openness for elementary computational concepts. This project is financed by Technology Alliance Upper Franconia, Hermann-Gutmann-Stiftung, and the internal research funding of the University of Bamberg.

\section{REFERENCES}

[1] Baylor, A. L. and Ritchie, D. 2002. What factors facilitate teacher skill, teacher morale, and perceived student learning in technology-using classrooms? In: Computers \& Education 39, 395-414.

[2] Bell, T., Witten, I., and Fellows, M. 2015. Computer Science Unplugged. An Enrichment and Extension Programme for Primary-Aged Students. Adapted for classroom use by Adams R. and McKenzie., J. URL: http://csunplugged.org/.
[3] Bingimlas, K. A. 2009. Barriers to the successful integration of ICT in teaching and learning environments: A review of the literature. In: Eurasia Journal of Mathematics, Science \& Technology Education 5, 3, 235-245.

[4] Blumenfeld, P. C., Soloway, E., Marx, R.W., Krajcik, J. S., Guzidal, M. and Palincsar, A. 1991. Motivating projectbased learning: sustaining the doing, supporting the learning. Educational Psychologist 26, 3-4, DOI= http://dx.doi.org/10.1080/00461520.1991.9653139

[5] Bortz, J. and Döring, N. 2006. Quantitative Methoden der Datenerhebung [Quantitative Methods of Data Collection]. Springer Verlag, Berlin.

[6] Dewey, J. 1916. Democracy and education. In: Studies in Education 5, 1-2 (Spring/ Fall 2008), 87-95.

[7] Gentner, D., Levine, S. C., Dhillon, S., Ping, R., Bradley, C., Isaia, A., and Honke, G. 2016. Rapid learning in a children's museum via analogical comparison. Cognitive Science 40, 224-240.

[8] Grell, F. 2013. Frühkindliche Bildung in historischer Perspektive [Early childhood education in a historical perspective]. In Handbuch frühkindliche Bildungsforschung, M. Stamm and D. Edelmann, Ed. Springer Verlag, Wiesbaden, 147-164.

[9] Howard, K., Flanagan, S., Castine, E., and Walsh, M. 2015. Perceived influences on the career choices of children and youth: an exploratory study. International Journal for Education and Vocational Guidance, 15, 99-111.

[10] Janka, P. 2008. Using a programmable toy at preschool Age: Why and how? Workshop Proceedings of SIMPAR 2008. Intl. Conf. on Simulation, Modeling and Programming for Autonomous Robots, Venice (Italy) November,3-4, 112-121.

[11] Keane, M., Ledgeway, T., and Duff, S. 1994. Constraints on analogical mapping: A comparison of three models. Cognitive Science 18, 387-438.

[12] Patrick, H., Mantzicopoulos, P., and Samarapungavan, A. 2009. Motivation for learning science in kindergarten: Is there a gender gap and does integrated inquiry and literacy instruction make a difference. Journal of Research in Science Teaching 46, 2, 166-199.

[13] Plowman, L. \& Stephen, C. 2003. A ‘benign addition'? Research on ICT and pre-school children. In: Journal of Computer Assisted Learning 19, 149-164.

[14] Randolph, J., Julnes, G., Sutinen, E., and Lehman, S. 2008. A methodological review of computer science education research. Journal of Information Technology Education 7, 135-162.

[15] Roussou, M. 2004. Learning by doing and learning through play: An exploration of interactivity in virtual environments for children. In: ACM Computers in Entertainment 2, 1, Article 1.

[16] Schmid, U., Wirth, J., Polkehn, K. 2003. A closer look at structural similarity in analogical transfer. In: Cognitive Science Quarterly 3, 1, 57-89.

[17] Worth, K. 2010. Science in early childhood classrooms: content and process. In SEED Papers, Collected Papers from the STEM in Early Education and Development Conference (Cedar Falls, Iowa, USA, May 2010) 